\title{
Molecular characterization and pathogenesis of transmissible gastroenteritis coronavirus (TGEV) and porcine respiratory coronavirus (PRCV) field isolates co-circulating in a swine herd
}

\author{
L. Kim, J. Hayes, P. Lewis, A. V. Parwani, K. O. Chang, and L. J. Saif \\ Food Animal Health Research Program, Department of Veterinary Preventive Medicine, \\ Ohio Agricultural Research and Development Center, \\ The Ohio State University, Wooster, Ohio, U.S.A.
}

Accepted December 19, 1999

Summary. TGEV replicates in intestinal enterocytes and causes diarrhea in young pigs. PRCV, a spike (S) gene deletion mutant of TGEV with an altered respiratory tissue tropism, causes mild or subclinical respiratory infections. Comparisons of TGEV and PRCV strains suggest that tropism and pathogenicity are influenced by the $S$ gene and ORF3, respectively. Recently, outbreaks of TGE of reduced virulence were reported in the field. We investigated a similar suspect TGEV outbreak of reduced virulence in nursery pigs from a swine herd in the Midwest. A TGEV strain (BW021898B) was isolated in swine testicular cells from gut contents of a diarrheic pig and three PRCV strains (BW126, BW154, BW155) were isolated from nasal swabs from normal TGEV-seronegative sentinel pigs in contact with the diarrheic pigs. Sequence analysis of the TGEV isolate in the partial S gene and ORF3/3a and ORF3-1/3b revealed high homology with enteropathogenic TGEV strains. Gnotobiotic pig inoculation and histopathological results revealed that this TGEV isolate retained virulence even though in the field outbreak the diarrheal disease was of reduced severity. Sequence analysis of the $\mathrm{S}$ gene deletion region of the three PRCV isolates revealed identical deletions between nt 105-752, which differ from deletions previously reported among PRCV strains. The three PRCV isolates had variable sequence changes in ORF $3 / 3 \mathrm{a}$ and ORF 3-1/3b, affecting the ORF size and amino acid sequence. Thus, sequence analysis and pathogenicity studies indicate that this TGEV isolate resembles other enteropathogenic TGEV strains. Therefore, the reduced severity of TGE observed in this herd may be due to the ongoing PRCV infections, which induce antibodies 
cross-reactive with TGEV and result in decreased disease severity. The results outlined in this study highlight the need to monitor the molecular epidemiology of TGEV/PRCV strains with sensitive differential diagnostic assays, followed by sequence analysis of the critical regions to identify changes and pathogenicity studies to confirm the disease potential of the TGEV isolates.

\section{Introduction}

Transmissible gastroenteritis coronavirus (TGEV) causes severe gastroenteritis in young TGEV seronegative pigs $[13,20]$. The porcine respiratory coronavirus (PRCV) is a deletion mutant of TGEV with altered respiratory tissue tropism $[13,20]$. TGEV replicates primarily in small intestinal enterocytes and to a lesser extent in the respiratory tract [20]. PRCV replicates almost exclusively in the respiratory tract [13]. These viruses have 3 major structural proteins: the spike $(\mathrm{S})$, the integral membrane $(\mathrm{M})$ glycoprotein, and the nucleocapsid $(\mathrm{N})$ protein $[13,24]$. TGEV and PRCV strains produce $7-8$ subgenomic mRNAs during viral replication and each mRNA consists of $3^{\prime}$ co-terminal nested sets $[13,26]$. The $S$, $\mathrm{M}$ and $\mathrm{N}$ proteins are translated from mRNAs 2, 5 and 6, respectively. The mRNA 3, 3-1 (designated for Miller strain of TGEV) or mRNA 3a, 3b (designated for Purdue-115, FS722 strains of TGEV) encode two putative nonstructural proteins $[13,26]$.

Based on sequence comparisons of PRCV and TGEV, PRCV has a large deletion in the $5^{\prime}$ region of the $S$ gene, and minor deletions in genes $3 / 3 a$ and 3 $1 / 3 \mathrm{~b}[13,26]$. The deletions in the PRCV S gene and ORF 3 a region differ slightly between the European and US PRCV isolates [16, 26]. Some investigators have suggested that mutations or deletions in ORF 3a play a role in the reduced ability of PRCV to multiply in the intestine [18]. The consensus recognition sequences CTAAAC exist upstream of each open reading frame $[13,26]$. In PRCV, this sequence upstream of ORF $3 / 3 \mathrm{a}$ gene is partially deleted or altered $[22,26]$. The $\mathrm{S}$ protein has a membrane anchoring domain, is highly glycosylated and is thought to be the viral attachment protein which interacts with the cell receptor, porcine aminopeptidase $\mathrm{N}(\mathrm{APN})[11,22]$. The $\mathrm{S}$ protein of TGEV has four major antigenic sites, with site A being the major inducer of neutralizing antibodies [21]. Site A has been found to be highly conserved among TGEV and PRCV strains [7]. Because most viral neutralization (VN) antibodies are directed to antigenic site $\mathrm{A}, \mathrm{VN}$ or most conventional serologic assays fail to differentiate between pigs infected with PRCV or TGEV. The deletion size in the S gene of PRCV ranges from 621-681 nt depending on the strain $[13,21,26]$ and due to this deletion, there is a loss of one to two antigenic sites (C and B, or D) depending on the nomenclature $[11,21]$. Loss of this antigenic site(s) is the basis for a differential blocking ELISA test to serologically differentiate between pigs infected with PRCV or TGEV [23].

Many TGEV mutants arising from point mutations or recombinations have been reported [11, 13]. Point mutations in certain regions (amino acids 145-155) of the $\mathrm{S}$ gene may lead to loss of sialic acid binding activity affecting hemag- 
glutination (HA) [11, 22]. These mutations/recombinations may affect viral tissue tropism and virulence of strains [1]. Studies have suggested that amino acid changes at the $\mathrm{N}$-terminal region of the TGEV S protein are important for TGEV enteric tropism $[1,2]$. Alterations in an $\mathrm{S}$ gene region (around nucleotide number 655) were reported to affect the enteric tropism of the PUR46 strain of TGEV [1]. The ORF 3/3a and ORF 3-1/3b genes of virulent TGEV remain intact with only a few amino acid changes, but there is variability among the same genes of PRCV [13, 26, 27]. The size and location of deletions in these PRCV genes varied depending on the strain [26]. It has also been hypothesized that ORF 3/3a and ORF3-1/3b may be related to viral virulence and pathogenesis [18, 26, 27], but a recent study described a virulent strain of TGEV which has a large deletion in the ORF 3a gene [14].

Recently, diarrhea outbreaks associated with TGEV were reported with reduced severity in the field [19]. We have also investigated a similar suspect TGEV outbreak of reduced severity (mild diarrhea and intestinal lesions, slow disease spread among pigs) in nursery pigs from a swine herd in the Midwest, presumably complicated by the presence of antibodies to PRCV as confirmed by a differential blocking ELISA test on sera from a number of pigs in this herd (Saif LJ and Lewis P, unpubl.). Our hypothesis was that either these new TGEV strains represent naturally occurring recombinants of reduced virulence between TGEV and PRCV strains, or that the presence of PRCV antibodies in these herds complicated the diagnosis and modulated the severity of virulent TGEV infections. We characterized various molecular and pathologic properties of these isolates to clarify the significance of reduced TGEV disease severity in this herd.

Therefore, our objectives were to isolate and characterize TGEV and PRCV strains from this field outbreak to determine their genetic relationships to each other and to reference TGEV and PRCV strains. We also examined the virulence of the TGEV isolate in gnotobiotic pigs. We focused on the $S$ gene deletion area and ORF 3/3a and ORF 3-1/3b because previous studies [15, 18] have suggested that these regions may influence viral tissue tropism, replication and virulence [14]. Such information is important for our understanding of the changing epidemiology of TGEV/PRCV infections and for continued efforts to design more efficacious vaccines.

\section{Materials and methods}

Source herd, viruses and cells

We recently investigated a suspect TGEV outbreak of reduced virulence (mild diarrhea and intestinal lesions, slow disease spread among pigs) in nursery pigs (3-5 weeks post-weaning) from a Midwest swine herd. Diagnosis of TGEV in these pigs was sporadic and inconsistent and presumably complicated by the presence of cross-reactive antibodies to PRCV, confirmed by a blocking differential ELISA test on sera from a number of pigs in this herd (Saif LJ and Lewis P, unpubl.). Four field samples described here were obtained from the herd. The BW021898B specimen consisted of intestinal contents from a nursery pig with mild diarrhea (clinically suspect for TGEV). Three nasal swab samples (BW126, BW154 and BW155) were obtained from normal TGEV-seronegative sentinel nursery pigs placed in 
contact with the diarrheic nursery pigs. Each isolate was cell culture adapted and plaquepurified in swine testicular (ST) cells : BW021898B *6(2), BW126*7(2), BW154*4(1), BW155*8(2) [ Number of times passaged in cell culture (number of times plaque-purified)] The ST cells were used for virus isolation, propagation and cell culture immunofluorescence tests (CCIF) as previously described [3, 23, 25].

\section{Reverse transcriptase polymerase chain reaction and nested PCR}

To differentiate TGEV/ PRCV directly from the field cases and from the cell culture adapted isolates, RT-PCR primers F1(5'-GGGTAAGTTGCTCATTAGAAATAATGG 3') and R1 (5'CTTCTTCAAAGCTAGGGACTG-3'), and the nested PCR primers F2 (5' - TTGTGGTYTTGGTYGTAATKCC-3') and R2 (5'-GGCTGTTTGGTAACTAATTTRCCA-3') associated with the open reading frame (ORF) $1 \mathrm{~b}$ and the $\mathrm{S}$ gene deletion areas for US and Europe strains of PRCV were used [17]. Viral RNA was extracted using previously described procedures $[5,17,26]$. The plaque purified TGEV/PRCV isolates from the infected culture lysates were mixed with $4 \mathrm{M}$ guanidinium thiocyanate, $25 \mathrm{mM}$ sodium citrate, $\mathrm{pH} 7.0,0.5 \%$ sarcosyl, 0.1 M 2-mercaptoethanol [5] and $2 \mathrm{M}$ sodium acetate (pH 5.0). RNA was extracted with an equal volume of phenol/chloroform/isoamyl alcohol and purified using silicon matrix (Bio101, CA). The RT-PCR reaction contained $10 \times$ PCR buffer (Promega, WI), $5 \mu l$ of $25 \mathrm{mM} \mathrm{MgCl}_{2}, 1 \mu \mathrm{l}$ of $10 \mathrm{mM}$ dNTP, $20 \mathrm{U}$ RNasin (Promega), $5 \mathrm{U}$ AMV-reverse transcriptase (Promega) and 2.5 U Taq DNA polymerase (Promega) and $0.5 \mu$ of $50 \mathrm{pmol}$ of each primer. Reaction mixtures were incubated at $55^{\circ} \mathrm{C}$ for $45 \mathrm{~min}$, followed by $95^{\circ} \mathrm{C}$ for $5 \mathrm{~min}$. The following parameters were used for amplification: 25 cycles at $94{ }^{\circ} \mathrm{C}$ for $1 \mathrm{~min}, 60^{\circ} \mathrm{C}$ for $1.5 \mathrm{~min}, 72^{\circ} \mathrm{C}$ for $2.5 \mathrm{~min}$ with final extension at $72{ }^{\circ} \mathrm{C}$ for $10 \mathrm{~min}$. Diluted amplicons were used as templates for nested PCR. For nested PCR, we used 1 cycle of $95^{\circ} \mathrm{C}$ for $5 \mathrm{~min}$, 25 cycles of $94^{\circ} \mathrm{C}$ for $1 \mathrm{~min}, 62^{\circ} \mathrm{C}$ for $1.5 \mathrm{~min}, 72^{\circ} \mathrm{C}$ for $2.5 \mathrm{~min}$ with a final extension at $72{ }^{\circ} \mathrm{C}$ for $10 \mathrm{~min}$. PCR products were analyzed on $1.5 \%$ agarose gels stained with ethidium bromide $[17,26]$.

Sequencing of the partial $S$ gene and ORF 3/3a, 3-1/3b genes of the isolated TGEV/PRCV strains

The TGEV isolate (BW 021898B) and the PRCV isolates (BW126, BW154, BW155) were used for sequence analysis of the partial $\mathrm{S}$ region with primers $\mathrm{F} 1, \mathrm{R} 1$ and ORF $3 / 3 \mathrm{a}$ and 3-1/3b regions with primers F3, R3 [16] and F4, R4 [12]. PCR products were purified using a Geneclean II kit (Bio101, CA) and sequenced by dideoxynucleotide chain termination procedures using an automated sequencer [ABI 377, Perkin-Elmer, CA]. Sequence data were aligned using the Genetics Computer Group Sequence analysis software package (GCG) and DNAstar software and compared with the published sequences.

\section{Gnotobiotic pig inoculation with the TGEV BW021898B strain}

Four hysterectomy-derived and colostrum-deprived 11-day-old gnotobiotic pigs were oronasally inoculated with the cell culture adapted, plaque-purified BW021898B TGEV isolate $\left[2 \times 10^{7}\right.$ plaque forming units $(\mathrm{PFU}) / \mathrm{pig}, \mathrm{n}=3$ ] or with $4.5 \mathrm{ml}$ of a $1: 10$ dilution of the original field fecal specimen [BW021898B, $8.4 \times 10^{3}$ fluorescent focus forming units $(\mathrm{FFU}) / \mathrm{ml}, \mathrm{n}=1]$. As a control, an uninfected pig was also included in this study. Clinical parameters including diarrhea and fecal scores $(0=$ normal, $1=$ pasty, $2=$ semiliquid, $3=$ liquid) were recorded. Rectal and nasal viral shedding were assayed by CCIF and RTPCR/nested PCR (Kim L. et al., unpubl.) from days post inoculation (DPI) 1 to 4. Pigs were euthanized at the onset of diarrhea or at 7 DPI. Sections of duodenum, jejunum, ileum and lung were collected for immunofluorescence assay (IFA). Impression smears were made on 
glass microscope slides, air dried and fixed in acetone [3]. For histopathology studies, tissues were processed in Prefer fixative solution (Anatech LTD, Battle Creek, MI), embedded in paraffin, sectioned at $5 \mu \mathrm{m}$ and stained with hematoxylin and eosin (HE), before examining microscopically [3]. At least seven villi and crypts of each intestinal tissue were observed. Villous atrophy was scored for each villous section, and assigned a value as follows: $0=$ normal, $2=$ moderate, $3=$ marked, $4=$ severe. Villous: crypt ratios were determined by measuring the heights of the villi, the lengths of adjacent crypts and then calculating the ratios.

\section{Cell culture immunofluorescence test (CCIF) and indirect immunofluorescence assay (IFA)}

Nasal and rectal swabs collected from gnotobiotic pigs inoculated with BW021898B strain were diluted in MEM and tested by CCIF using previously described procedures [3, 23, 25]. Briefly, four-fold serial dilutions of supernatants were inoculated onto ST cell monolayers in 96-well plates and incubated for $18 \mathrm{~h}$. The cells were fixed with $80 \%$ acetone, stained with hyperimmune porcine anti-TGEV serum conjugated to fluorescein isothiocyanate (FITC) and analyzed by fluorescent microscopy.

Antigenicity tests to differentiate the TGEV/PRCV isolates using monoclonal antibodies to TGEV, were performed using ST cell monolayers in 96-well microplates, inoculated with the TGEV Miller strain (M5C), the PRCV ISU-1 strain or the field isolates at concentrations producing infectivity in 60 to $80 \%$ of the ST cells by $20 \mathrm{~h}$ as determined by CCIF $[3,23,25]$. Infected cells were washed with PBS and fixed with $80 \%$ acetone. Monoclonal antibodies $(25 \mathrm{C} 9,44 \mathrm{C} 11)$ against sites $\mathrm{A}$ and $\mathrm{D}$, respectively [23] of the $\mathrm{S}$ protein were added for 30 min followed by FITC-labeled anti-mouse IgG (KPL, MD) for $30 \mathrm{~min}$. The FITC-labeled $\mathrm{IgG}$ was aspirated and monolayers were washed with PBS and viewed using fluorescent microscopy.

\section{Results}

\section{Molecular characterization of TGEV and PRCV field strains}

After confirmation of the field isolates as TGEV or PRCV by RT-PCR and nested PCR methods (Fig. 1), the 4 field isolates were adapted to growth in ST cells and plaque purified. The partial $S$ gene deletion area, ORF 3/3a and ORF 3-1/3b of these 4 cell culture adapted field isolates were sequenced. This region of the $\mathrm{S}$ gene contains the known antigenic site D (in Paris nomenclature, 13) (Fig. 2) $[11,23]$. The TGEV isolate BW021898B had higher nucleotide (nt) homology with the virulent Miller strain of TGEV than with the attenuated Purdue strain (PUR46MAD) or respiratory TGEV (NEB72) in this partial S gene area, ORF3/3a and ORF3-1/3b (Figs. 3-5). The BW021898B strain also had higher amino acid (aa) homology with the virulent TGEV strain in this partial S gene encoding area which is known to affect the enteropathogenicity of TGEV strains (Fig. 3). The TGEV isolate had 72 aa residues encoded by the ORF3/3a gene and 244 aa residues encoded by the ORF3-1/3b gene (Figs. 4, 5). There was a 3 nucleotide deletion in the noncoding region upstream of ORF3/3a (data not shown).

The three PRCV strains (BW126, BW154, BW155) had identical 648 nt deletions in the $\mathrm{S}$ gene starting from nt 105 to nt 752 (Figs. 2, 3), which differed in size and location from European PRCV or other U.S. PRCV strains (Figs. 2, 3). Sequence analysis revealed that the selected region of the $\mathrm{S}$ gene of the PRCV 


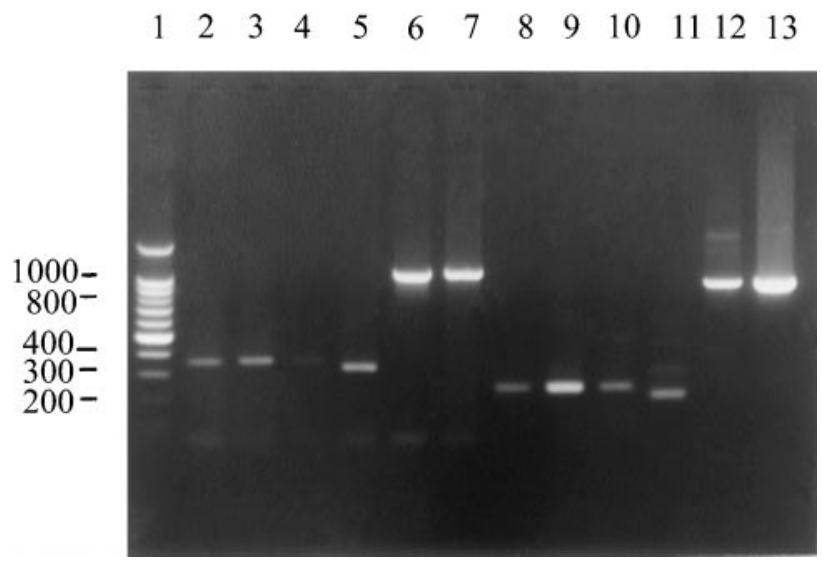

Fig. 1. RT-PCR and nested PCR products from original field samples. 2-7RT-PCR products, 8-13 Nested PCR products, L 1100 bp marker (Promega), 2, 8 BW126, 3, 9 BW154, 4, 10 BW155, 5, 11 ISU-1(PRCV), 6, 12 BW021898B, 7, 13 TGEV Miller. The expected RT-PCR product sizes were $1006 \mathrm{bp}$ for TGEV and were $325-385 \mathrm{bp}$ for PRCV strains. The expected nested PCR product sizes were 874 bp for TGEV and 192-253 bp for PRCV strains

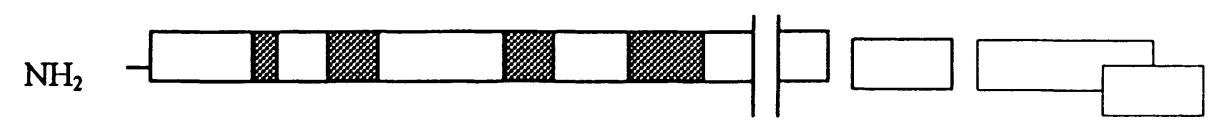

Antigenic sites

Paris

Madrid

TGEV CHV
TGEV BW021898B
PRCV AR310
PRCV IA1894
PRCV ISU-1

\begin{tabular}{ll} 
PRCV BW126 & 105 \\
PRCV BW154 & 105 \\
\hline PRCV BW155 & 105 \\
\hline
\end{tabular}

$\begin{array}{llll} & \mathrm{D} & \mathrm{C} & \mathrm{A} / \mathrm{B} \\ \mathrm{C} & \mathrm{B} & \mathrm{D} & \mathrm{A}\end{array}$

$\mathrm{A} / \mathrm{B}$
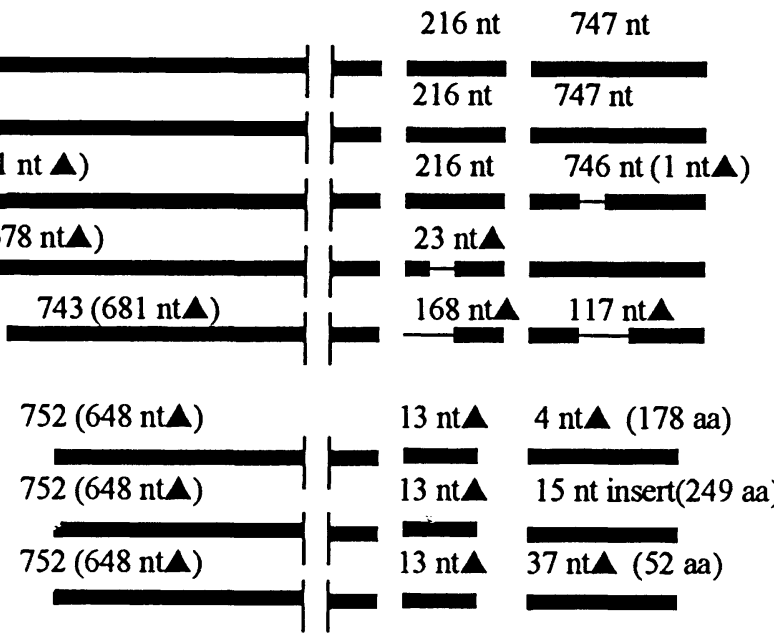

Fig. 2. Summary of genetic analysis of $S$ gene deletion area and ORF $3 / 3 a, 3-1 / 3 b$ of TGEV and PRCV strains [26]. $\boldsymbol{\Delta}=$ deletion size. The sequences for comparison were obtained from GenBank or previously published reports. TGEV: virulent CHV [26] and PRCV: AR310, IA1894 and ISU-1 [26]. Antigenic sites: Paris [13] and Madrid [21] 
Molecular characterization of TGEV/PRCV strains

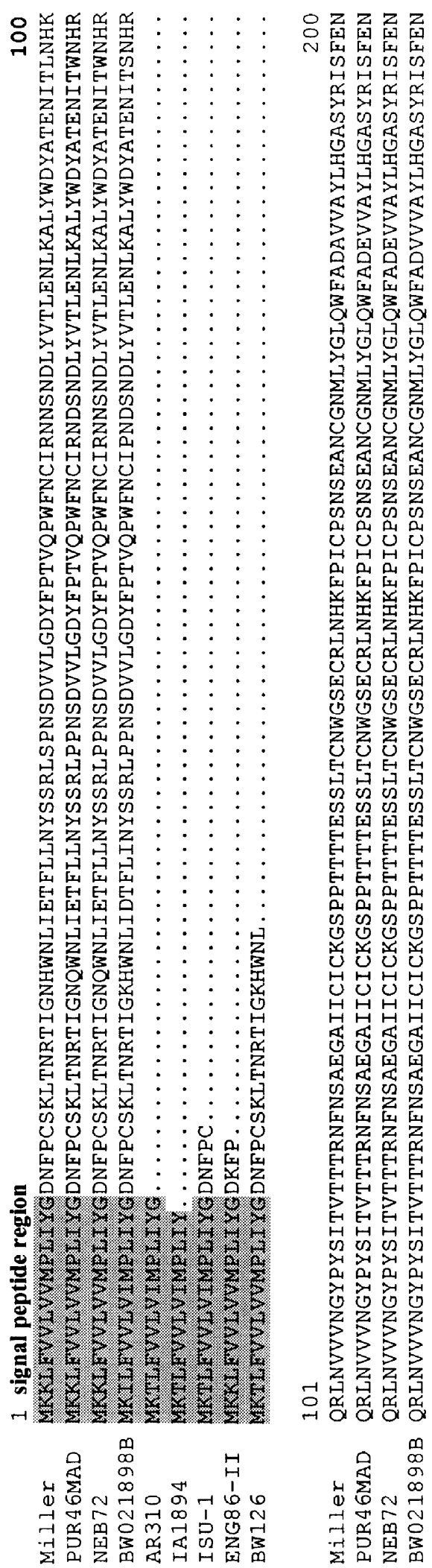

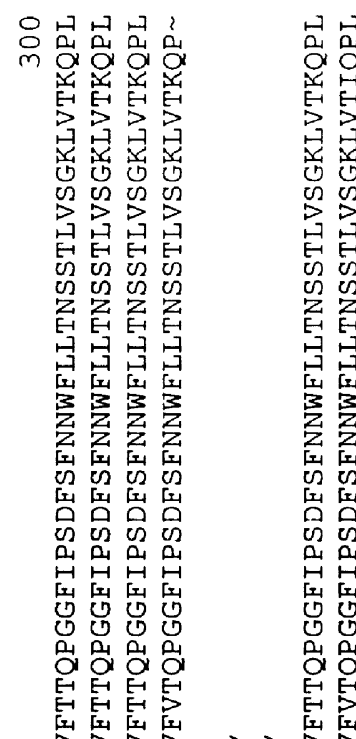

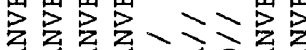

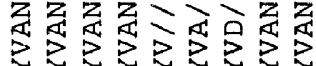

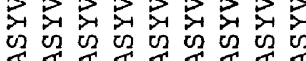

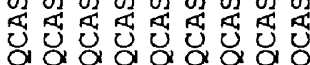

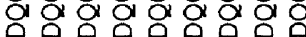

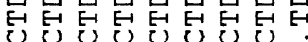

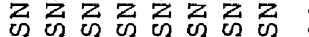

$333333>3$

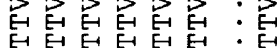

00000

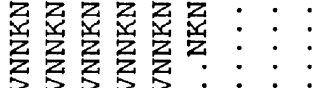

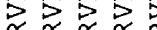

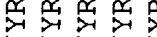

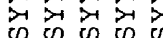

宫宫宫它:

त्र $\gg x \geqslant 2$

品品品品

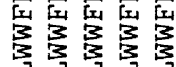

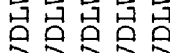

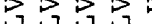

㫐舄舄舁:

瓜芯通:

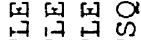

昆昆

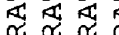

尛 $\Sigma$

이잉

星留留是

包兒兒昆

-1 w w w w

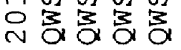

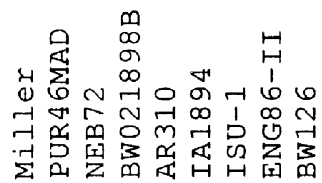

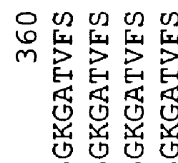

的 Uू

分分蚉

鼠

氙最

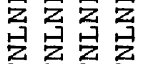

喝

定宫

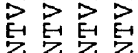

驾学驾

怎芯

己己己

o 잉요

㓶贸贸

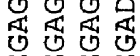

되 되 되 되

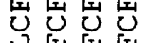

岳出出

\%

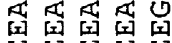

되 되되

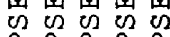

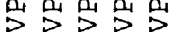

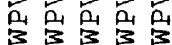

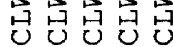

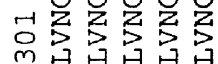

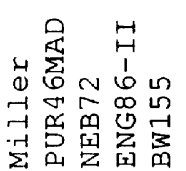

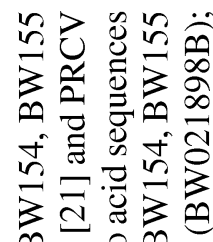

थ

ํำ

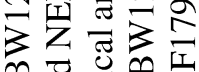

क

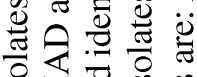

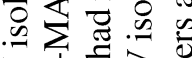

己过的主

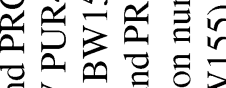

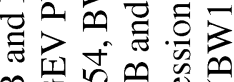

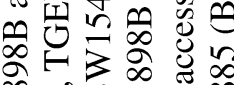

$\infty \dot{\sim} \infty$

तิ

兽品它

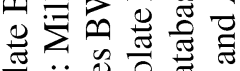

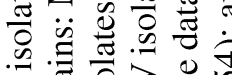



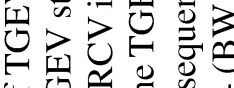

○䒘

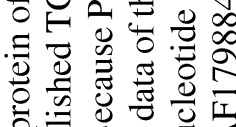

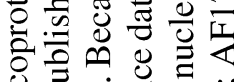

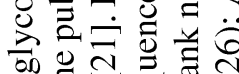

क

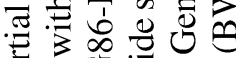

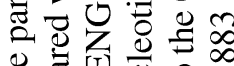

\&

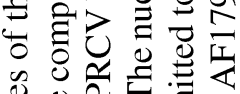

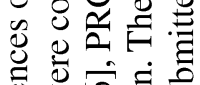

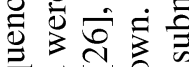

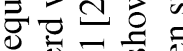

过它

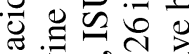

多市至

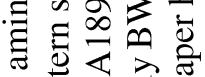

गे

음을

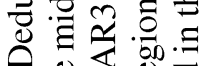

ค 连

ம் 


$\begin{array}{ll} & 1 \\ \text { CHV } & \text { MDIVKS INTSVDAVLDELDCAYFAVTLKVEFKTGKLLVCIGFGDTLLAARDKAYAKLGLSI IEEVNTQNPKH } \\ \text { Purdue115 } & \text { MDIVKSIYTSVDAVLDELDCAYFAVTLKVEFKTGKLLVCIGFGDTLLAAKDKAYAKLGLSI IEEVNSHIVVH } \\ \text { AR310 } & \text { MDIVKSINTSVDAVLDELDCAYFAVTLKVEFKTGKLLVCIGFGDTLLAARDKAYAKLGLATIEEVNTQNPKH } \\ \text { IA1894 } & \text { MDIGKSIITSVDAVLDLDCAYFAVTLKVEKTGKLLVIGFGTLLARGKAY } \\ \text { BW021898B } & \text { MDIVKSINTSVDAVLDELDCAYFAVTLKVEFKTGRLVCIGFGTLLAARDKAYAKLGLATIEEVNTQNPKH } \\ \text { BW126 } & \text { MDIVKSINISVDVVLDKLDCAYFAVILKLEFKTGKLLVCIVFGDTLFAAMLSLVSPLLKK }\end{array}$

Fig. 4. Deduced amino acid sequences of the ORF3/3a gene of TGEV isolate BW021898B and PRCV isolates BW126, BW154, BW155 from the midwestern swine herd were compared to the published TGEV: virulent CHV [26] and Purdue and PRCV: AR310 and IA1894 [26]. PRCV isolates BW126, BW154 and BW155 had identical amino acid sequences in this region. The nucleotide sequence data of the TGEV isolate BW021898B and PRCV isolates BW126, BW154, BW155 reported in this paper have been submitted to the GenBank nucleotide sequence database. The accession numbers are: AF179886 (BW021898B); AF179887 (BW126); AF179888 (BW154); and AF179889 (BW155)

and TGEV field isolates had higher homology to each other outside the deletion area than to the sequences for other TGEV and PRCV strains (Fig. 3). The three PRCV isolates had the same 90 nucleotide deletion including the leader sequence binding site (CTAAAC), with conservation of the ATG initiation codon in the ORF 3/3a (Fig. 4). The three PRCV isolates had identical 180 nucleotides in the ORF3/3a gene with 13 nt deletions. These deletions changed the amino acid sequence and the size of the ORF3/3a gene causing a frameshift with an early stop codon (Fig. 4). Because of this frameshift, aa residues 51 to 60 of all three PRCV strains were different from previously published PRCV strains and the TGEV strain, BW021898B (from the same herd) (Fig. 4). The three PRCV isolates had 3 nucleotide deletions upstream of ORF3-1/3b, but had intact leader sequence binding sites (CTAAAC) (data not shown). The three PRCV isolates had variable nucleotide deletions in ORF3-1/3b and these deletions influenced amino acid changes and ORF sizes in this gene area. The PRCV strain, BW126, had a 4 nucleotide deletion and 178 amino acid residues in ORF 3-1/3b (Figs. 2, 5). The PRCV strain, BW154, had 249 amino acids residues in ORF 3-1/3b and a 15 nucleotide insertion at the end of this gene (Figs. 2, 5). Because of a 37 nucleotide deletion in ORF 3-1/3b, which resulted in an early stop codon, the ORF 3-1/3b of BW155 retained only 52 amino acids (Figs. 2, 5).

Using the IFA with monoclonal antibodies $25 \mathrm{C} 9$ and 44C11 against antigenic sites A and D [23], respectively, BW021898B, BW126, BW154, BW155 had positive reactions with $25 \mathrm{C} 9$, but only BW021898B had a positive reaction using the differential monoclonal antibody (site D), 44C11.

\section{Pathogenesis of the TGEV field strain BW021898B}

Three gnotobiotic pigs were inoculated oronasally with the cell culture adapted TGEV BW021898B isolate $\left(2 \times 10^{7} \mathrm{PFU} / \mathrm{pig}\right)$, and one pig was inoculated with $4.5 \mathrm{ml}$ of a $10 \%$ filtrate of the original field pig intestinal contents sample $\left(8.4 \times 10^{3}\right.$ FFU/ml). In addition, one pig was mock-inoculated as a control. Clinical parameters including diarrhea and fecal scores were recorded after inoculation. All three pigs inoculated with the cell culture adapted BW021898B TGEV and the 
Molecular characterization of TGEV/PRCV strains

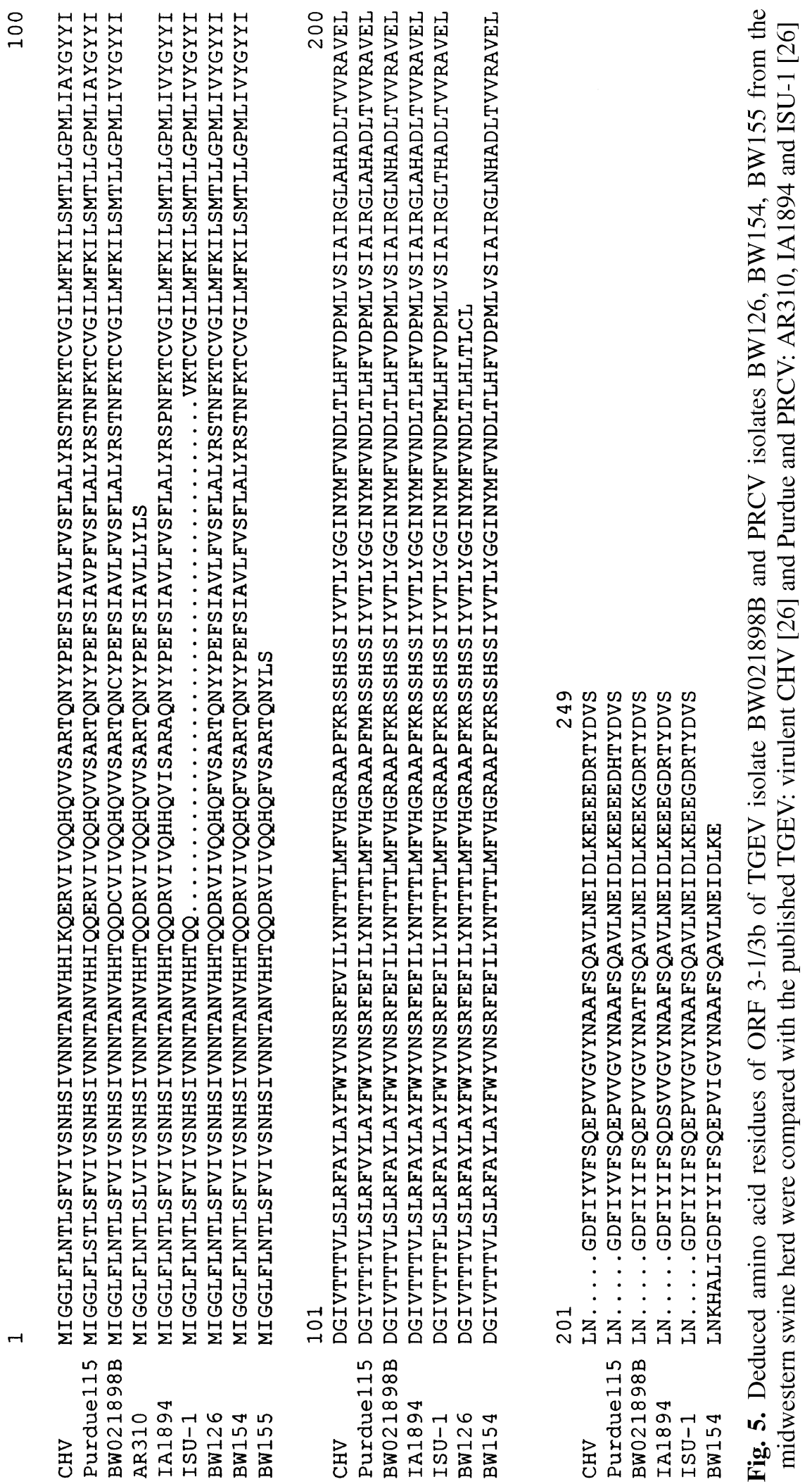


Table 1. Summary of histopathology results obtained after gnotobiotic pigs were inoculated with the TGEV field strain, BW021898B (or original intestinal contents)

\begin{tabular}{|c|c|c|c|c|c|c|c|c|c|c|}
\hline \multirow{3}{*}{$\begin{array}{l}\text { Pig } \\
\text { number }\end{array}$} & \multirow[t]{3}{*}{ DPI } & \multicolumn{9}{|c|}{ Intestinal segment } \\
\hline & & \multicolumn{3}{|c|}{ Duodenum } & \multicolumn{3}{|c|}{ Jejunum } & \multicolumn{3}{|c|}{ Ileum } \\
\hline & & $\begin{array}{l}\text { Vilous } \\
\text { atrophy } \\
\text { score }^{\mathrm{c}}\end{array}$ & $\begin{array}{l}\text { Villous: } \\
\text { crypt } \\
\text { ratios }\end{array}$ & $\begin{array}{l}\text { FA } \\
\text { smear }^{\text {d }}\end{array}$ & $\begin{array}{l}\text { Villous } \\
\text { atrophy } \\
\text { score }^{c}\end{array}$ & $\begin{array}{l}\text { Villous: } \\
\text { crypt } \\
\text { ratios }\end{array}$ & $\begin{array}{l}\text { FA } \\
\text { smear }\end{array}$ & $\begin{array}{l}\text { Villous } \\
\text { atrophy } \\
\text { score }^{\mathrm{c}}\end{array}$ & $\begin{array}{l}\text { Villous: } \\
\text { crypt } \\
\text { ratios }\end{array}$ & $\begin{array}{l}\text { FA } \\
\text { smear }\end{array}$ \\
\hline Mock infected & & 0 & $8: 1$ & & 0 & $4: 1$ & & 0 & $5: 1$ & \\
\hline GP $4-10^{\mathrm{a}}$ & $30 \mathrm{~h}$ & 0 & $4-7: 1$ & - & 3 & $2: 1$ & + & 2 & $3-5: 1$ & + \\
\hline GP $4-12^{b}$ & $46 \mathrm{~h}$ & 0 & $4-6: 1$ & + & 4 & $1: 1$ & + & 4 & $1: 1$ & + \\
\hline GP 4-9a & $53 \mathrm{~h}$ & 0 & $6-7: 1$ & - & 4 & $1: 1$ & + & 4 & $1: 1$ & - \\
\hline GP $4-11^{\mathrm{a}}$ & $7 \mathrm{DPI}$ & 0 & $4-5: 1$ & - & 1 & $4: 1$ & + & 1 & $2-4: 1$ & + \\
\hline
\end{tabular}

${ }^{\text {a }}$ These gnotobiotic pigs were inoculated with the cell culture adapted, plaque-purified BW021898B TGEV isolate $\left(2 \times 10^{7} \mathrm{PFU} / \mathrm{pig}\right)$

${ }^{\mathrm{b}}$ This gnotobiotic pig was inoculated with $4.5 \mathrm{ml}$ of a 1:10 dilution of the original intestinal contents (BW021898B, $8.4 \times 10^{3} \mathrm{FFU} / \mathrm{ml}$ )

${ }^{\mathrm{c}}$ Score is designated as $0=$ Normal, $1=$ Mild, $2=$ Moderate, $3=$ Marked, and $4=$ Severe

${ }^{\mathrm{d}}$ Mucosal smears were prepared as outlined in the text and stained with FITC-conjugated anti-TGEV serum

${ }^{\mathrm{e}}$ Villous and crypt lengths were measured and ratios of villous to crypt length were determined as an indication of the severity of lesions [20]

one pig given the original intestinal filtrate developed severe diarrhea after DPI 1 with fecal scores of 3 . Viral shedding was detected in rectal swab samples as early as DPI 1 and until DPI 4 by RT-PCR/nested PCR assays but only at DPI 1 using CCIF. Using nested PCR, virus was detected from nasal swab samples from DPI 1-4, but CCIF and RT-PCR failed to detect viral shedding from nasal swab samples. The highest TGEV titers determined by CCIF in small and large intestinal contents were at 30 hour post-inoculation of gnotobiotic pig 4-10 and were $2.4 \times 10^{10} \mathrm{FFU} / \mathrm{ml}$ and $5.2 \times 10^{8} \mathrm{FFU} / \mathrm{ml}$, respectively (Table 1 ). The IFA results for mucosal smears are summarized in Table 1. Segments of the duodenum, jejunum and ileum from infected animals or the control were sectioned and histopathological lesions were recorded and summarized (Table 1). Severe villous atrophy was noted in the jejunum and lesions characteristic of virulent TGEV were observed (Table 1). For the normal control piglet and the TGEV infected piglets, the villi-crypt ratios were also computed as summarized in Table 1 . There were no gross or macroscopic lesions in the lungs or any respiratory signs with the BW021898B TGEV strain (data not shown). IFA smear results on the lungs were negative.

\section{Discussion}

TGEV is a major cause of neonatal diarrhea in swine and also causes enzootic diarrhea in older pigs. Recently in the UK, isolated sporadic outbreaks of TGE 
in herds seropositive for PRCV antibodies were reported [19]. Unlike classical TGE, there was no evidence for high piglet mortality or disease spread to neighboring farms, even though the seroprevalence of TGEV antibodies in area herds was low (7.1\%). In addition weaned pigs that shed TGEV antigen in feces detected by ELISA had "non-specific looseness" resembling mild epidemic TGE: other swine had subclinical infections evident only by seroconversion to TGEV by differential ELISA. Unfortunately no TGEV isolates from these herds were available for study, but the investigators speculated that variant forms of TGEV or PRCV might be circulating in these infected herds. Similarly, atypical TGEV infections characterized by lower virulence and less rapid spread occurred recently in large nurseries in the midwestern U.S. in which some animals tested positive for antibodies to PRCV. Although such TGEV infections may be moderated by the presence of PRCV antibodies, it is conceivable that PRCV antibodies may also exert selective pressure for naturally-occurring variants of TGEV or for recombinants between TGEV and PRCV strains coinfecting the same pig. Such variants or recombinants may possess an intestinal tropism, but may be of reduced virulence. In this study we obtained field TGEV/PRCV specimens from a herd with a suspect TGEV infection of reduced disease severity and characterized these strains by cell culture adaptation, sequence analysis, antigen-based assays and histopathology. Our overall goal was to clarify if these field strains represented TGEV variants or natural recombinants between TGEV and PRCV strains or if the severity of diarrheal disease was reduced due to cross-reacting antibodies to TGEV from prior PRCV infections. We were also interested to see if these PRCV strains isolated from a single herd were identical or similar to one another and how related they were to TGEV isolates from the same herd. This type of information about the molecular epidemiology of naturally occurring TGEV/PRCV strains and their variability in disease severity is very important for understanding mechanisms of disease and the molecular identity of field strains.

We isolated a TGEV strain, BW021898B from the large intestinal contents of a diarrheic pig and three PRCV strains, BW126, BW154, BW155 from nasal swabs of clinically normal TGEV-seronegative sentinel nursery pigs placed in contact with the diarrheic pigs. We hypothesized that natural PRCV/TGEV recombinants or point mutations in TGEV (TGEV variants) may have been the cause of the reduced severity of diarrhea noted among pigs from the midwestern herd. We focused on analysis of the amino-terminal portion of the $S$ gene and the entire ORF 3 gene because both tropism and virulence differences among TGEV and PRCV strains have been attributed to deletions in these two genes [1, 13, 14, 18, 26]. All PRCV strains sequenced to date have 621-681 nt deletions within the amino-terminal $\mathrm{S}$ gene resulting in loss of hemagglutination activity [11] and 2 antigenic sites [7, 13, 21] including site D recognized by our Mab 44C11 [23]. In contrast enteric TGEV strains have intact S genes. Generally, virulent TGEV strains have intact ORF 3 genes, but attenuated TGEV strains have deletions or insertions that alter ORF 3 [13, 18, 26]. Similarly, virulent PRCV strains have an intact ORF 3a gene, whereas non-pathogenic PRCV strains have 
altered ORF 3 genes that render the gene or gene product non-functional [13, 18, 26]. Recently however, McGoldrick et al. [14] characterized a virulent TGEV strain (96-1033) with a major deletion in ORF 3a and suggested that ORF 3a may not be essential for enteric virulence. However, this deletion reduced the ability of the TGEV strain to grow in cell culture. Thus studies with a plaque-purified or cloned TGEV isolate were not possible to exclude the possibility of other virulent TGEVs in their original sample [14]. Similarly, Ballestros et al. [1] showed that changes in 2 amino acids in the amino-terminal portion of the $S$ protein resulted in the loss of the enteric tropism of TGEV without changes downstream of the $\mathrm{S}$ protein. Therefore, the role of ORF 3/3a and ORF 3-1/3b in viral replication and pathogenesis remains unclear.

Sequence analysis of the partial $\mathrm{S}$ gene, ORF3/3a and ORF3-1/3b revealed that the BW021898B strain had high homology with the virulent TGEV Miller strain with only a few aa changes. Pathogenicity studies of the cell culture adapted field virus (BW021898B) and the original intestinal sample demonstrated that this field strain retained enteropathogenicity and produced disease and histopathological lesions similar to virulent reference TGEV strains [20]. Our findings suggest that the mild diarrhea associated with TGEV in these nurseries is not related to attenuation of this TGEV strain because of point mutations or deletions in the partial S gene or to deletions in the ORF 3, but may be due to the partial crossprotective immunity induced in these pigs by PRCV which moderates the disease severity [25] and may influence the transmission of TGEV strains co-circulating in such herds.

The TGEV isolate had only a few aa changes in the partial S region in comparison to the virulent Miller strain or attenuated TGEV strains [21, 26, 30]. In previous studies, aa 219 of the $S$ protein (around nt 655) was reported to be related to enteric tissue tropism [1]. In this region, the TGEV BW021898B strain shared aa identity with the virulent enteric Miller TGEV strain and PUR46MAD both of which retain enteric tropism [1, 21] (Fig. 3). Also, the BW021898B strain had variable nucleotide changes in the partial $\mathrm{S}$ gene area, but these changes did not affect enteric tropism or virulence based on the pathogenicity studies in gnotobiotic pigs. The BW021898B had high homology with virulent TGEV in ORF 3 and 3-1 [26]. The ORF 3a gene usually has variable deletions depending on the strain and this gene is truncated in the attenuated TGEV variant strain SP and some PRCV strains [18, 26, 28].

The three PRCVs had an identical 648 nt deletion (216 aa) in the S gene containing antigenic site $\mathrm{D}[21,23]$ and failed to react with our differential monoclonal antibody $44 \mathrm{C} 11$ to site $\mathrm{D}$. The three PRCV isolates also had greater sequence homology in the partial S gene area with the BW021898B strain compared to other TGEV strains suggesting that these PRCV strains may have co-evolved with the BW021898B strain. The three PRCV strains retained ORF 3a but had a complete deletion of the leader sequence binding site and had variable deletions in ORF 3b, that may make the mRNAs undetectable or nonfunctional. All three PRCV strains were readily adapted to ST cells, suggesting that intact ORF 3 genes are not essential for viral growth in cell culture. However, additional sequence 
from the entire genome and from other strains from this herd should be analyzed to further confirm these observations.

In this study, prior PRCV or concurrent TGEV/PRCV infections in a herd may influence and change the pathogenesis of TGEV, thereby reducing the severity of disease $[13,25]$. Such a reduction in TGEV disease severity followed by disappearance of TGEV was noted in some European swine herds following the appearance of PRCV strains [13,20]. Findings from studies such as ones described here improve our understanding of changes in the molecular epidemiology of PRCV/TGEV infections under natural conditions and should be useful for the design of more efficacious vaccines.

\section{Acknowledgements}

We thank Dr. Qijing Zhang for advice and Ms. Kathy Gadfield for technical assistance. Salaries and research support were provided by state and federal funds appropriated to the Ohio Agricultural Research and Development Center (OARDC), The Ohio State University. This study was supported in part by the Pig Improvement Company (PIC), Franklin, KY, the HANOR Company, Inc, Spring Green, WI, and the National Pork Producer's Council on behalf of the U.S. National Pork Board.

\section{References}

1. Ballesteros ML, Sanchez CM, Enjuanes L (1997) Two amino acid changes at the Nterminal of the of transmissible gastroenteritis coronavirus spike protein result in the loss of enteric tropism. Virology 227: 378-388

2. Bernard S, Laude H (1995) Site-specific alteration of transmissible gastroenteritis virus spike protein results in markedly reduced pathogenicity. J Gen Virol 76: 2235-2 241

3. Bohl EH, Saif LJ, Theil KW, Agnes AG, Cross RF (1982) Porcine pararotavirus: detection, differentiation from rotavirus, and pathogenesis in gnotobiotic pigs. J Clin Microbiol 15: 312-319

4. Britton P, Page KW (1990) Sequence of the S gene from a virulent British field isolate of transmissible gastroenteritis virus. Virus Res 18: 71-80

5. Chomczynski P, Sacchi N (1987) Single-step method of RNA isolation by acid guanidinium thiocyanate-phenol-chloroform extraction. Anal Biochem 162: 156-159

6. Cox E, Pensaert MB, Callebaut P, VanDeun K (1990) Intestinal replication of PRCV closely related antigenically to the enteric transmissible gastroenteritis virus. Vet Microbiol 23: 237-243

7. Delmas B, Rasschaert D, Godet M, Gelfi J, Laude H (1990) Four major antigenic sites of the coronavirus transmissible gastroenteritis virus are located on the amino-terminal half of the spike glycoprotein S. J Gen Virol 71: 1313-1323

8. Godet M, L'Haridon R, Vautherot JF, Laude H (1992) TGEV coronavirus ORF4 encodes a membrane protein that is incorporated into virions. Virology 188: $666-675$

9. Jacobs L, Vander Zeijst BAM, Horzinek MC (1986) Characterization and translation of transmissible gastroenteritis virus mRNAs. J Virol 57: 1 010-1015

10. Kapke PA, Brian DA (1986) Sequence analysis of the porcine transmissible gastroenteritis coronavirus nucleocapsid protein gene. Virology 151: 41-49

11. Krempl C, Schultze B, Laude H, Herrler G (1997) Point mutations in the S protein connect the sialic acid binding activity with the enteropathogenicity of transmissible gastroenteritis coronavirus. J Virol 71: 3285-3 287 
12. Kwon HM, Saif LJ, Jackwood DJ (1998) Field isolates of transmissible gastroenteritis virus differ at the molecular level from the Miller and Purdue virulent and attenuated strains and from porcine respiratory coronaviruses. J Vet Med Sci 60: 589-597

13. Laude H, Reeth KV, Pensaert M (1993) Porcine respiratory coronavirus: molecular features and virus-host interactions. Vet Res 24: 125-150

14. McGoldrick A, Lowings JP, Paton DJ (1999) Characterization of a recent virulent transmissible gastroenteritis virus from Britain with a deleted ORF 3a. Arch Virol 144: 763-770

15. O'Connor JB, Brian DA (1999) The major product of porcine transmissible gastroenteritis coronavirus gene $3 \mathrm{~b}$ is an integral membrane glycoprotein of $31 \mathrm{kDa}$. Virology 256: $152-161$

16. Page KW, Mawditt KL, Britton P (1991) Sequence comparison of the 5'end of mRNA3 from transmissible gastroenteritis virus and from porcine respiratory coronavirus. J Gen Virol 72: 579-587

17. Paton D, Ibata G, Sands J, McGoldrick A (1997) Detection of transmissible gastroenteritis virus by RT-PCR and differentiation from porcine respiratory coronavirus. J Virol Methods 66: 303-309

18. Paul PS, Vaughn EM, Halbur PG (1997) Pathogenicity and sequence analysis studies suggest potential role of gene 3 in virulence of swine enteric and respiratory coronaviruses. In: Paul PS, Francis DH, Benfield DA (ed) Mechanisms in the pathogenesis of enteric diseases. Plenum Press, New York, pp 317-321

19. Pritchard GC, Paton DJ, Wibberley G, Ibata G (1999) Transmissible gastroenteritis and porcine epidemic diarrhoea in Britain. Vet Rec 144: 616-618

20. Saif LJ, Wesley RD (1999) Transmissible gastroenteritis and porcine respiratory coronavirus. In: Straw BE, D'Allaire S, Mengeling WL, Taylor DJ (eds) Diseases of swine 8th ed. Iowa State University Press, Ames, pp 295-325

21. Sanchez CM, Gebauer F, Sune C, Mendez A, Dopazo J, Enjuanes L (1992) Genetic evolution and tropism of transmissible gastroenteritis coronavirus. Virology 190: 92105

22. Schultze B, Krempl C, Ballesteros ML, Shaw L, Schauer R, Enjuanes L, Herrler G (1996) Transmissible gastroenteritis coronavirus, but not the related porcine respiratory coronavirus, has a sialic acid (N-Glycolylneuraminic acid) binding activity. J Virol 70: 5634-5637

23. Simkins RA, Weilnau PA, Bias J, Saif LJ (1992) Antigenic variation among transmissible gastroenteritis virus (TGEV) and porcine respiratory coronavirus.strains detected with monoclonal antibodies to the S protein of TGEV. Am J Vet Res 53: 1253-1 258

24. Spaan W, Cavanagh D, Horzinek C (1988) Coronaviruses: structure and genome expression. J Gen Virol 69: 2939-2 952

25. VanCott JL, Brim TA, Lunney JK, Saif LJ (1994) Contribution of antibody-secreting cells induced in mucosal lymphoid tissues of pigs inoculated with respiratory or enteric strains of coronavirus to immunity against enteric coronavirus challenge. J Immunol 152: 3 980-3990

26. Vaughn EM, Halbur PG, Paul PS (1995) Sequence comparison of porcine respiratory coronavirus isolate reveals heterogenecity in the S, 3 and 3-1 genes. J Virol 69: $3176-3184$

27. Wesley RD, Woods RD, Cheung AK (1991) Genetic analysis of porcine respiratory coronavirus, an attenuated variant of transmissible gastroenteritis virus. J Virol 65: 3369 3373

28. Wesley RD, Woods RD, Cheung AK (1990) Genetic basis for the pathogenesis of transmissible gastroenteritis virus. J Virol 64: 4761-4766 
29. Wesley RD, Cheung AK, Michael DD, Woods RD (1989) Nucleotide sequence of coronavirus TGEV genomic RNA: evidence for 3 mRNA species between the peplomer and matrix protein genes. Virus Res 13: 87-100

30. Wesley RD (1991) Nucleotide sequence of the E2-peplomer protein gene and partial nucleotide sequence of the upstream polymerase gene of transmissible gastroenteritis virus (Miller strain). Adv Exp Med Biol 276: 301-306

Authors' address: Dr. J. Saif, 1680 Madison Avenue, Food Animal Research Program, Ohio Agricultural Research and Development Center, The Ohio State University, Wooster, OH, 44691, U.S.A.

Received August 23, 1999 